\title{
A new route to prepare nanocomposites based on polyvinyl chloride and MgAl layered double hydroxide intercalated with laurylether phosphate
}

\author{
N. H. Huang ${ }^{1,2 *}$, J. Q. Wang 3 \\ ${ }^{1}$ Key Laboratory of Green Processing and Functional Textiles of New Textile Materials, Ministry of Education, Wuhan \\ University of Science and Engineering, Wuhan, 430073, P.R. China \\ ${ }^{2}$ Department of Polymer Science and Engineering, Wuhan University of Science and Engineering, Wuhan, 430073, \\ P.R. China \\ ${ }^{3}$ National Laboratory of Flame Retardant Materials, Beijing Institute of Technology, Beijing, 100081, P.R. China
}

Received 10 May 2009; accepted in revised form 26 June 2009

\begin{abstract}
The $\mathrm{MgAl}$ layered double hydroxide (LDH) with laurylether phosphate was prepared using reconstruction method. Delamilation of the LDH with laurylether phosphate (LDH-PK) in tetrahydrofuran was characterized by AFM (atomic force microscopy), indicating that a large part of the LDH was delaminated into single, double and multi layers. The delaminated LDH-PK suspension was then used with polyvinyl chloride (PVC) to prepare a series of high-LDH-loading nanocomposites. Both the XRD (X-ray diffraction) patterns and TEM (transmission electron microscopy) photographs of the as-prepared PVC/LDH nanocomposites indicated that the LDH nanolayers dispersed uniformly in the PVC matrix. With differential scanning calorimetry (DSC) the glass transition temperatures of PVC phases in the PVC/LDH nanocomposites were measured and a slightly lower value than that of pristine PVC has been observed. Thermogravimetric analysis results show that the presence of LDH enhanced the dehydrochlorination temperature $\left(T_{\max 1}\right)$, reduced the maximum degradation rate $\left(R_{\max 1}\right)$ and the $5 \%$ weight loss temperature, and promoted the char formation of PVC. However, the thermal degradation temperature $\left(T_{\max 2}\right)$ and thermal degradation rate $\left(R_{\max 2}\right)$ of the dehydrochlorinated PVC were slightly affected by the presence of LDH. The apparent activation energies were calculated by the method of Flynn-Wall-Ozawa in nitrogen at four different heating rates, showing that the nanofiller increased the apparent activation energies by $10-26 \mathrm{~kJ} / \mathrm{mol} \mathrm{when}$ compared with pristine PVC, probably implying that the LDH nanolayers improve the stability of chlorine atom on the PVC chains.
\end{abstract}

Keywords: nanocomposites, polyvinyl chloride, layered double hydroxide, thermal properties, exfoliation-restacking

\section{Introduction}

In recent years polymer nanocomposites based on layered double hydroxides (LDHs) have attracted considerable attention because they can be considered to be reinforced by the nanofiller and follow the various unique properties such as enhanced mechanical properties, thermal stability, and reduced flammability [1-7]. LDHs are lamellar structured hydrotalcite-like compounds with anionic exchange properties. Their general chemical formula is $\left[\mathrm{M}_{\mathrm{x}}^{\mathrm{II}} \mathrm{M}_{1-\mathrm{x}}^{\mathrm{III}}(\mathrm{OH})_{2}\right]^{\mathrm{x}+}\left[\mathrm{A}_{\mathrm{x} / \mathrm{m}}^{\mathrm{m}} \cdot n \mathrm{H}_{2} \mathrm{O}\right]$, where $\mathrm{M}^{\mathrm{II}}, \mathrm{M}^{\mathrm{III}}$, and $\mathrm{A}^{\mathrm{m}-}$ represent divalent metal cation (like $\mathrm{Mg}^{2+}, \mathrm{Zn}^{2+}, \mathrm{Ni}^{2+}$, etc.), trivalent metal cation (like $\mathrm{Al}^{3+}, \mathrm{Cr}^{3+}$, etc.), and the interlayer anion (like $\mathrm{CO}_{3}^{2-}, \mathrm{Cl}^{-}, \mathrm{SO}_{4}^{2-}$, and various organic carboxylates, sulfates, sulfonates), respectively, where $n$ is the number of associated water molecules [8]. The ability to exchange the interlayer anions intro- 
duces provides a opportunity via which known flame retardant anions, such as $\mathrm{PO}_{4}^{3-}$, can be incorporated into the lamellar structure before adding the $\mathrm{LDH}$ to a polymer.

In general, polymer/LDH nanocomposites can be prepared via four major methods [9], i.e. in situ polymerization, direct intercalation, exfoliation restacking and coprecipitation. Amongst the methods, the exfoliation restacking method is especially suitable for the preparation of nanocomposites based on thermosensitive polymers such as poly(vinyl chloride). Wherein, the LDH was stepwise exfoliated into single, double and mutilayers in the proper solvents and afterwards transformed into a colloidal system and finally, the colloidal system was precipitated in the presence of the polymer. However, pristine LDHs is generally not liable to be exfoliated in solvent because of the high charge density on the layers. Recently, to modify the LDHs with organic anions has been found to be a successful strategy for exfoliation in solvent [10-12]. As reported by Adachi-Pagano et al. [11], the ZnAl-LDH modified with dodecyl sulfate may be a way efficiently delaminated in formamide. Later, Hibino and Jones [12] also reported that glycinate-containing MgAl-LDH was delaminated in formamide at room temperature. The laurylether phosphate (PK) was taken in the laboratory as a modifier to realize the preparation of laurylether phosphate intercalated LDH (LDH-PK), which was successfully exfoliated under the reflux in tetrahydrofuran solvent.

Poly(vinyl chloride) (PVC) is known as one of the widely used and low cost thermoplastics. Recently, Bao et al. [13] reported that partially intercalated and partially exfoliated PVC/MgAl-LDH nanocomposites were prepared by in situ suspension polymerization of vinyl chloride monomer in the presence of LDHs modified with dodecyl sulfate anions (LDH-DS). The fully exfoliated PVC/ $\mathrm{MgAl}-\mathrm{LDH}$ nanocomposites were prepared via a melt-compounding process by Chen [14], later, via solution intercalation $[15,16]$. It is noted that special vessels are usually required and the toxic monomer is indispensable during these processing. The solution process may provide the most desirable conditions to prevent thermal and oxidative degradation during preparation [17]. Very few studies on the PVC/MgAl-LDH nanocomposites have been documented in literatures through novel exfoliation restacking route using laurylether phosphate intercalated LDH. In this regard we report the subject at low temperature. A preliminary study is on the exfoliation behavior of LDH-PK in tetrahydrofuran solvent using atomic force microscopy (AFM). Structure, thermal properties and thermal degradation kinetics of the PVC/LDH nanocomposites were followed in the next part by XRD, TEM, TG (thermogravimetry) and DSC.

\section{Experimentals}

\subsection{Materials}

PVC (density $1.36 \mathrm{~g} / \mathrm{cm}^{3}$, the number average molecular weight $7.8 \cdot 10^{4}$ ) was purchased from Hubei Yihua Chemical Industry Co. Ltd, China. $\mathrm{Mg}\left(\mathrm{NO}_{3}\right)_{2} \cdot 6 \mathrm{H}_{2} \mathrm{O}, \mathrm{Al}\left(\mathrm{NO}_{3}\right)_{3} \cdot 9 \mathrm{H}_{2} \mathrm{O}$, and urea was analytical grade purchased from Sinopharm Group Chemical Reagent Co. Ltd, China, and used without further purification. Aqueous solution of potassium laurylether phosphate (PK) (30 wt $\%$ in water) was purchased from Dandong Ankang Chemical Industry Co. Ltd, China.

\subsection{Preparation of $\mathrm{MgAl}-\mathrm{LDH}-\mathrm{CO}_{3}$}

$\mathrm{LDH}-\mathrm{CO}_{3}$ was synthesized by urea hydrolysis method described by Costantino et al. [18]. An aqueous solution containing $\mathrm{Al}\left(\mathrm{NO}_{3}\right)_{3}$ and $\mathrm{Mg}\left(\mathrm{NO}_{3}\right)_{2}$ with the molar fraction $\mathrm{Al}\left(\mathrm{NO}_{3}\right)_{3} /$ $\left(\mathrm{Al}\left(\mathrm{NO}_{3}\right)_{3}+\mathrm{Mg}\left(\mathrm{NO}_{3}\right)_{2}\right)$ equal to 0.33 was prepared by dissolving $\mathrm{Al}\left(\mathrm{NO}_{3}\right)_{3}$ and $\mathrm{Mg}\left(\mathrm{NO}_{3}\right)_{2}$ in distilled water. To this solution solid urea was added until the molar fraction urea/ $\left(\mathrm{Mg}\left(\mathrm{NO}_{3}\right)_{2}+\mathrm{Al}\left(\mathrm{NO}_{3}\right)_{3}\right)$ reached 3.3. The clear solution was refluxed for $36 \mathrm{~h}$. The white precipitate was then filtered, washed five times by doubly distilled water and dried in vacuum at $60^{\circ} \mathrm{C}$ till constant weight.

\subsection{Preparation of the layered double hydroxide- laurylether phosphate (LDH-PK)}

$\mathrm{LDH}-\mathrm{CO}_{3}$ was calcined in a muffle furnace at $450^{\circ} \mathrm{C}$ for about $6 \mathrm{~h}$ to convert it into metal oxide. The calcined product (CLDH) was dispersed in a $120 \mathrm{ml}$ of aqueous solution containing $6 \mathrm{~g}$ of potassium laurylether phosphate (PK) and the dispersion was stirred by magnetic stirrer for $24 \mathrm{~h}$ at $25^{\circ} \mathrm{C}$ under flowing Ar. The regenerated PK intercalated 
LDH (LDH-PK) was filtered out followed by drying in vacuum at $60^{\circ} \mathrm{C}$.

\subsection{Preparation of PVC/LDH nanocomposites}

A schematic representation of the preparation of the PVC/LDH nanocomposite is shown in Figure 1. LDH-PK was firstly refluxed in $100 \mathrm{ml}$ tetrahydrofuran for $24 \mathrm{~h}$ under flowing Ar with mechanical stirring. After treatment, the exfoliated LDH material was achieved by dispersing LDH-PK in tetrahydrofuran. A desired amount of PVC was dissolved in tetrahydrofuran solvent, and then the $\mathrm{PVC} /$ tetrahydrofuran solution was added to the LDH-PK suspension. After stirring for $3 \mathrm{~h}$ at $60^{\circ} \mathrm{C}$ under flowing $\mathrm{Ar}$, the mixture was poured into $50 \mathrm{ml}$ absolute ethanol for rapid precipitation in order to avoid aggregation of the LDH platelets. The precipitate was filtered and dried at $60^{\circ} \mathrm{C}$ under flowing Ar for 12 hours.

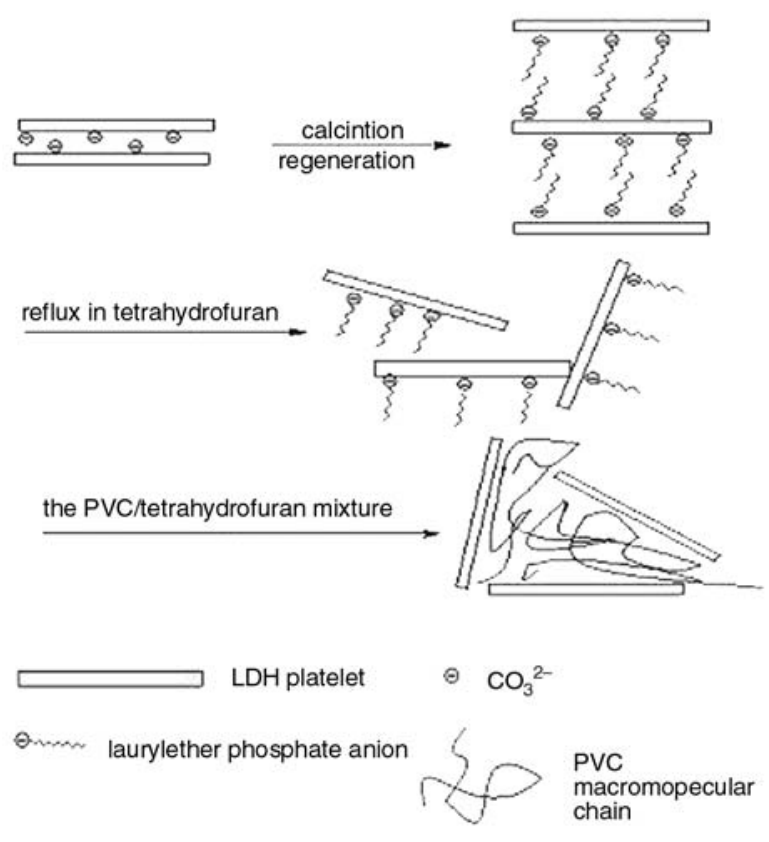

Figure1. Schematic representation of the preparation of the PVC/LDH nanocomposites

\subsection{Characterization}

\subsubsection{Atomic Force Microscopy (AFM)}

Atomic Force Microscopy (AFM) can be used to investigate the delamination behaviour of $\mathrm{LDH}$ in solvent and the thickness of the exfoliated nanosheets in the colloid dispersion [10]. AFM was performed using a Nanoscope E multimode AFM from digital instruments. The instrument was operated in tapping mode in air at room temperature. A Si tip with a diameter smaller than $10 \mathrm{~nm}$ (Mikronmasch) was used to achieve high resolution. Height and amplitude-mode images were recorded simultaneously with $512 \times 512$ pixel resolution and $1-2 \mathrm{~Hz}$ scan rate. Processing and analyses of the images were carried out using the off-line software Nanoscope. A concentration $(0.1 \mathrm{~g} / \mathrm{l})$ of exfoliated LDH in tetrahydrofuran was used for AFM. One drop of the clear dispersion was dripped onto a freshly cleaved mica surface $\left(1 \times 2 \mathrm{~cm}^{2}\right)$. The sample was then conditioned at room temperature for $24 \mathrm{~h}$ and kept at $60^{\circ} \mathrm{C}$ for $48 \mathrm{~h}$. Freshly cleaved mica has locally a very smooth surface with a an average roughness of $c a .0 .1 \mathrm{~nm}$.

\subsubsection{X-ray diffraction analysis (XRD)}

$\mathrm{X}$-ray diffraction analysis (XRD) over $2 \theta=1.2$ $65^{\circ}$, in steps of $0.02^{\circ}$ was carried out using a Rigaku $2600 \mathrm{X}$-ray diffractometer with $\mathrm{Cu}-\mathrm{K}_{\alpha}$ radiation $(\lambda=0.15418 \mathrm{~nm}$, monochromatization by primary graphite crystal) generated at $30 \mathrm{~mA}$ and $40 \mathrm{kV}$.

\subsubsection{Fourier Transform Infrared (FTIR) spectroscopy}

Fourier transform infrared (FTIR) spectra for samples were recorded over the wave number range $400-4000 \mathrm{~cm}^{-1}$ using Bruker Tensor 27 FTIR spectrometer.

\subsubsection{Thermal analysis}

Thermogravimetric analysis (TG) was performed on the NETZSCH thermal analyzer (TG 209 F1). Samples weighting about $5.0 \mathrm{mg}$ were heated from room temperature to $700^{\circ} \mathrm{C}$ in a dynamic nitrogen atmosphere $(50 \mathrm{ml} / \mathrm{min})$. For kinetic analysis of the thermal degradation, TGA experiments of some samples were performed at four different heating rates, such as $5,10,20,40^{\circ} \mathrm{C} / \mathrm{min}$. DSC data was measured by a NETZSCH DSC-204F1 at heating rate of $10^{\circ} \mathrm{C} / \mathrm{min}$ with $\mathrm{N}_{2}$ purging $(50 \mathrm{ml} / \mathrm{min})$.

\subsubsection{Transmission electron microscopy (TEM)}

The state of aggregation of the LDH particles in PVC matrix was investigated by TEM, which was 
carried out using transmission electron microscope with JEOL 2010 (HT) microscope. The conditions used during analysis were room temperature, $200 \mathrm{kV}$ acceleration voltage and bright field illumination. The ultra thin sections of samples, which were embedded in an epoxy oligomer polymerized at $50^{\circ} \mathrm{C}$ for $48 \mathrm{~h}$, were prepared by ultramicrotomy at $-130^{\circ} \mathrm{C}$ using Reichert Ultracut $\mathrm{S}$ (Leica, Austria). The thickness of the section cut was in the range of $70-80 \mathrm{~nm}$.

\section{Results and discussion}

\subsection{Characterization of LDHs}

The FTIR spectra of the $\mathrm{LDH}-\mathrm{CO}_{3}$, its calcined form (CLDH) and its regenerated form (LDH-PK) are shown in Figure 2. Figure 2a reveals the presence of interlayer carbonate ions $\left(1361 \mathrm{~cm}^{-1}\right)$ and the associated water molecules appeared within the broad range of $3150-3600 \mathrm{~cm}^{-1}$ in $\mathrm{LDH}-\mathrm{CO}_{3}$, where the hydrogen bonding in the interlayer region between water molecules and the hydroxide sheet is evident from shoulder at $3050-3100 \mathrm{~cm}^{-1}$. In Figure $2 b$, the loss of interlayer carbonate anions and water molecules results in the weakening of the corresponding peaks. The weakened broad peak around $3400 \mathrm{~cm}^{-1}$ is possibly attributed to some adsorbed water molecules on the surface of CLDH [5]. In Figure 2c the reapprearance of the $\mathrm{O}-\mathrm{H}$ peak (stretching vibration peak) takes place with the disappearance of the shoulder existed in the original LDH. Other peaks can be easily assigned as follows: 2928 and $2853 \mathrm{~cm}^{-1}$ (aliphatic $\mathrm{C}-\mathrm{H}$ stretch);

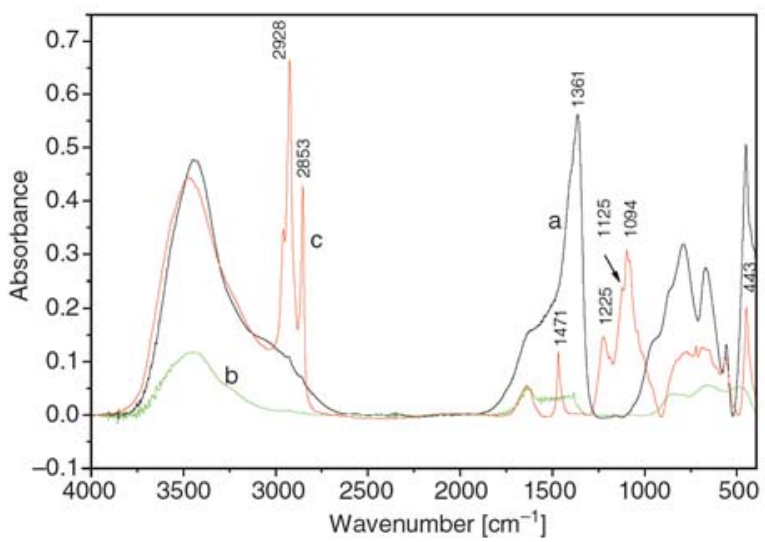

Figure 2. FTIR spectra of $\mathrm{LDH}-\mathrm{CO}_{3}$ (a), its calcined product (CLDH) (b) and LDH-PK (c)

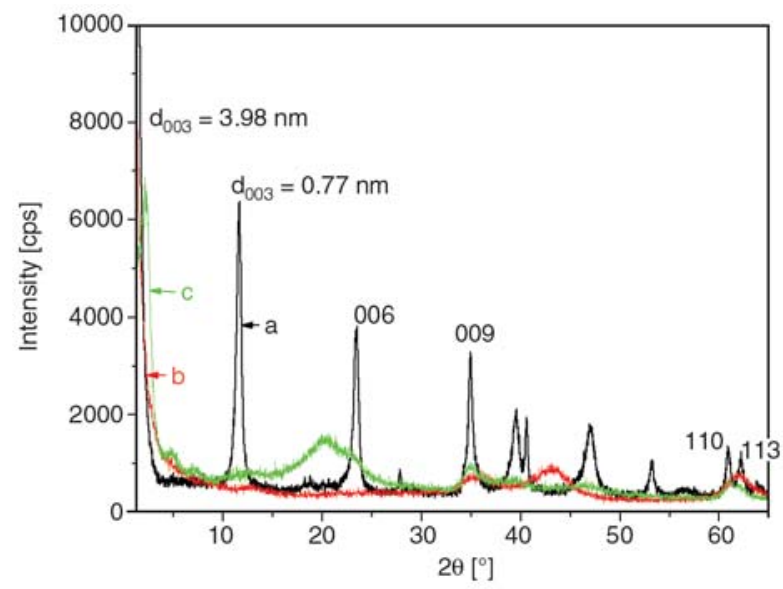

Figure 3. XRD spectra of $\mathrm{LDH}-\mathrm{CO}_{3}$ (a), its calcined product (CLDH) (b) and LDH-PK (c)

$1225 \mathrm{~cm}^{-1}$ (the $\mathrm{P}=\mathrm{O}$ bond); $1125,1094 \mathrm{~cm}^{-1}$ (the $\mathrm{P}-\mathrm{O}-\mathrm{C}$ bond).

The sharp and distinct peaks appeared in the XRD pattern (Figure 3a) give an indication of the highly crystalline nature in the synthesized $\mathrm{LDH}-\mathrm{CO}_{3}$ and layered geometry. Close to the assignment and the value of $0.78 \mathrm{~nm}$ reported by Chibwe and Jones [19] a value of $0.77 \mathrm{~nm}\left(2 \theta=11.4^{\circ}\right)$ of the basal peak (003) was measured. After calcination, CLDH loses all the peaks characteristic of layered structure as well as $\mathrm{MgAl}$ layer crystal structure, just as indicated in the Figure 3b. Again, Figure $3 \mathrm{c}$ also supported the subsequent recovery of the original structure by dispersing CLHD into an aqueous solution of laurylether phosphate. The XRD pattern of regenerated material (LDH-PK) (Figure 3c) shows a basal spacing of $3.98 \mathrm{~nm}\left(2 \theta=2.14^{\circ}\right)$. The space between the $\mathrm{Mg} / \mathrm{Al}$ nanolayers of the $\mathrm{LDH}$ PK larger than that of pure $\mathrm{LDH}-\mathrm{CO}_{3}$ confirms an enlargement of interlayer distance from 0.77 to $3.98 \mathrm{~nm}$. Based on FTIR and XRD results one could believe the intercalation of the laurylether phosphate into the LDHs. The increase of interlayer distance $\left(\Delta d_{L}\right)$ in the LDH-PK, calculated from the $d_{003}$ spacing and thickness of the inorganic layer (estimated to $0.48 \mathrm{~nm}$ ), is approximately $3.5 \mathrm{~nm}$. However, according to the individual dodecyl sulphate chain length (ca. $2 \mathrm{~nm}$ ) [2], the individual laurylether phosphate chain length is close to $2 \mathrm{~nm}$. This leads to the conclusion that the orientations of PK in the gallery of LDHs may be essentially inclined bilayer (see Figure 1). 


\subsection{AFM images of delaminated LDH-PK in tetrahydrofuran}

A representative AFM images of delaminated LDH-PK deposited on a mica substrate can be shown in Figure 4. A thin layer of well dispersed nanoparticles lying parallel to the substrate surface is observed in Figure 4a, and the size and shape of individual particles are better visible. Figure $4 \mathrm{~b}$ shows a cross section of individual particles along the marked green line. The particles are disk-like with diameters of typically $30-60 \mathrm{~nm}$. Particles with different thicknesses of $0.7 \sim 5 \mathrm{~nm}$ are observed, which may correspond to single, double and multi hydrotalcite layers. Very small amount of particles with heights of up to $10 \mathrm{~nm}$ may tend to cause the aggregation of delaminated single or double nanosheets during volatilization of tetrahydrofuran solvent.

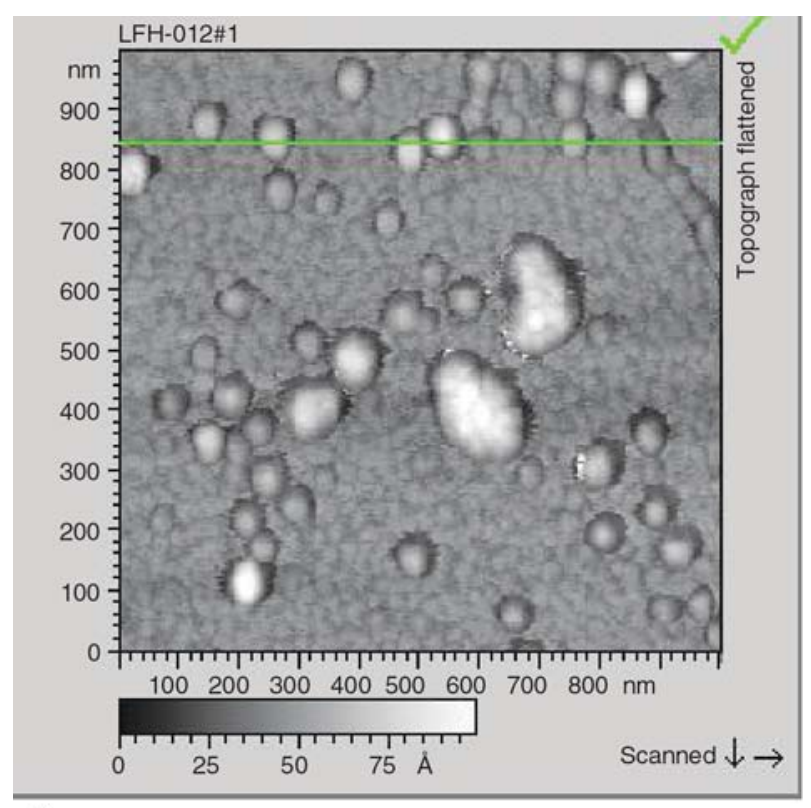

a)

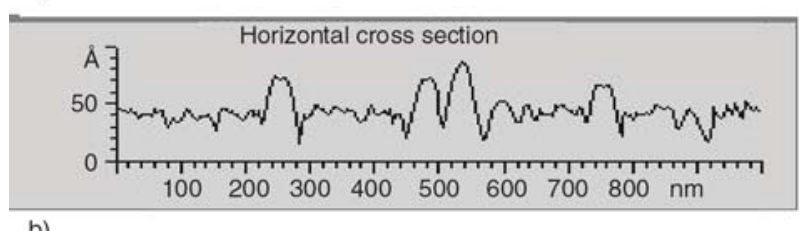

Figure 4. AFM images (tapping mode) of exfoliated LDH-PK in tetrahydrofuran $(0.1 \mathrm{~g} / \mathrm{l})$ deposited on a mica substrate. Height image over a scanning area of $1000 \times 1000 \mathrm{~nm}^{2}$ (a); section profile along the marked green line, showing single, double and multi layers of exfoliated LDH (b).

\subsection{XRD and TEM analysis of PVC/LDH nanocomposites}

The X-ray diffraction (XRD) patterns of the LDH$\mathrm{PK}$ and PVC/LDH composites are shown in Figure 5 within the range of $2 \theta=1.2-10^{\circ}$. The changes in structure spread out before us through the study on the diffraction patterns with different loadings of LDH-PK. The basal spacing of the LDH-PK sample presented itself at $3.98 \mathrm{~nm}(2 \theta=$ $2.14^{\circ}$ ). While at a loading of $50 \%$, the diffraction peaks below $2 \theta=3^{\circ}$ retained rather weaker (Figure 5f) and almost nothing left below 30\% in Figures $5 \mathrm{a}$ to $5 \mathrm{e}$, implying that the $\mathrm{PVC} / \mathrm{LDH}$ nanocomposite with high loading of LDH can be obtained by exfoliated-restacking method.

Figure 6 shows the TEM images of PVC/LDH nanocomposite with $20 \mathrm{wt} \% \mathrm{LDH}$. The low magnification TEM image showed the LDHs to be well dispersed throughout the polymer. Higher magnification showed that the $\mathrm{LDH}$ are exfoliated to $\mathrm{LDH}$ nanolayers in the PVC matrix, but intercalated tactoids were also present.

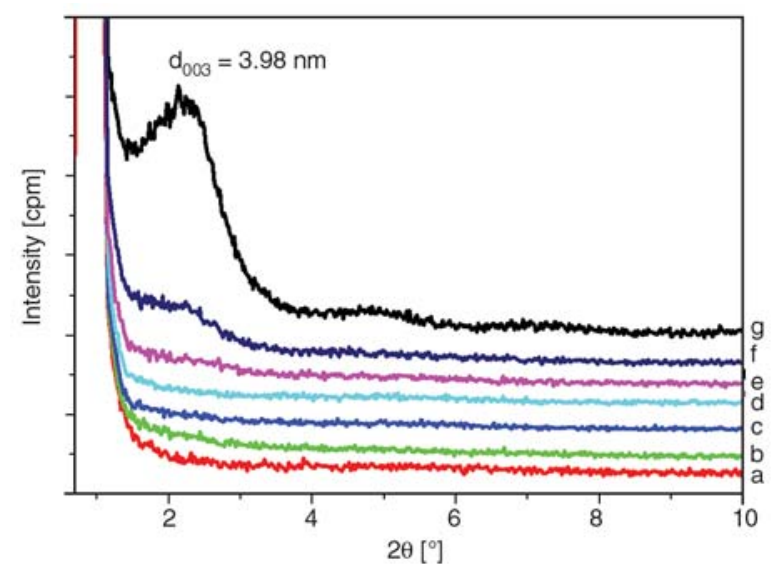

Figure 5. Variation of XRD patterns with the different loadings of LDH in the PVC/LDH nanocomposite samples in the range of 1.2 to $10^{\circ} 2 \theta$ :

(a) $5 \mathrm{wt} \%$, (b) $10 \mathrm{wt} \%$, (c) $15 \mathrm{wt} \%$, (d) $20 \mathrm{wt} \%$, (e) $30 \mathrm{wt} \%$, (f) $50 \mathrm{wt} \%$, (g) $100 \mathrm{wt} \%$

\subsection{DSC analysis}

Figure 7 shows DSC curves of pristine PVC and the PVC/LDH nanocomposites. The glass transition temperature $\left(T_{g}\right)$ of the nanocomposites with 2 and $5 \% \mathrm{LDH}$ are 84.9 and $84.6^{\circ} \mathrm{C}$, respectively, slightly lower than that of pristine $\mathrm{PVC}\left(85.4^{\circ} \mathrm{C}\right)$ in agreement with the value in PVC/MMT nanocomposites [20] and PP/MMT nanocomposites [21]. 


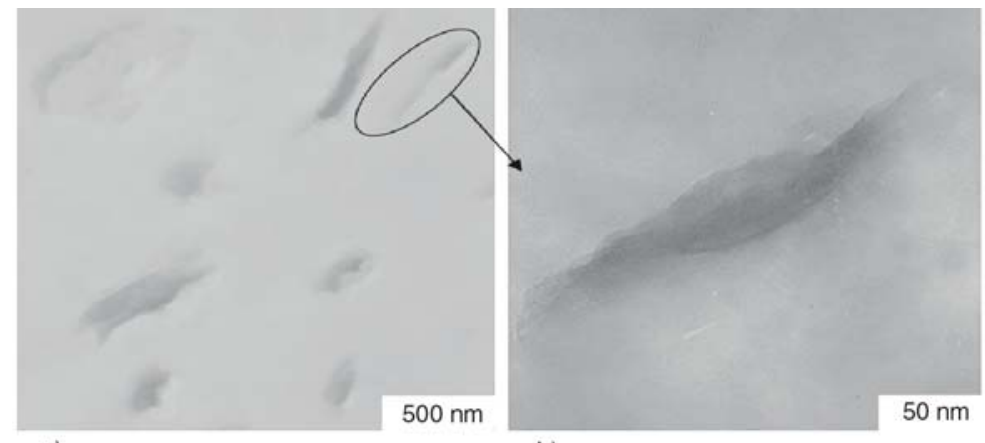

a)

b)

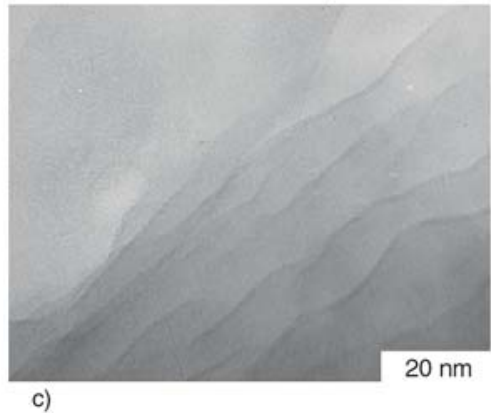

Figure 6. TEM micrographs of PVC/LDH nanocomposites with $20 \%$ loading of LDH

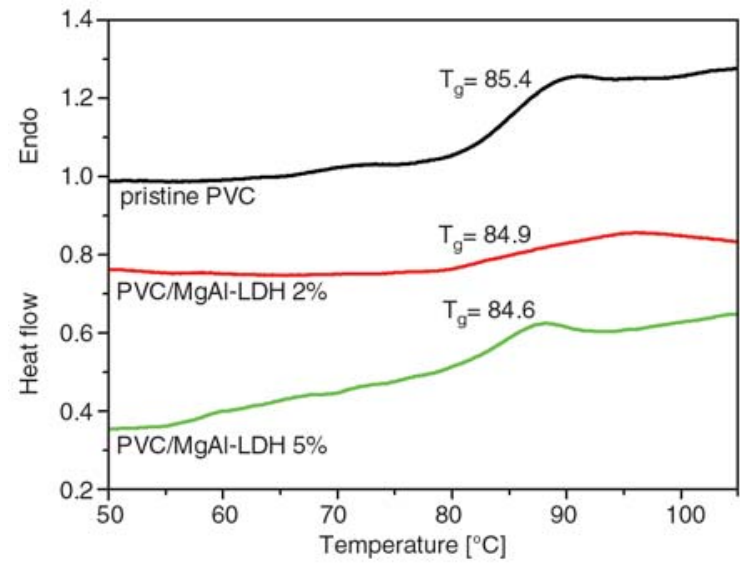

Figure 7. DSC curves of PVC and PVC/LDH nanocomposites with different loading of $\mathrm{LDH}$

Similarly, the LDH layers nano-dispersed in PVC matrix taking PVC macromolecules apart, rendering the interaction between macromolecular chains in nanocomposites weakened [20] and resulting in the decrease of the glass transition temperature of PVC phases in the PVC/LDH composite. In addition, it is possible that the PVC matrix was slightly plasticized by some of laurylether phosphate, and this resulted in the decrease of the $T_{g}$ of PVC phases.

\subsection{TG study}

To exemplify the thermal behaviour the TG and DTG curves of pristine PVC and its nanocompos-

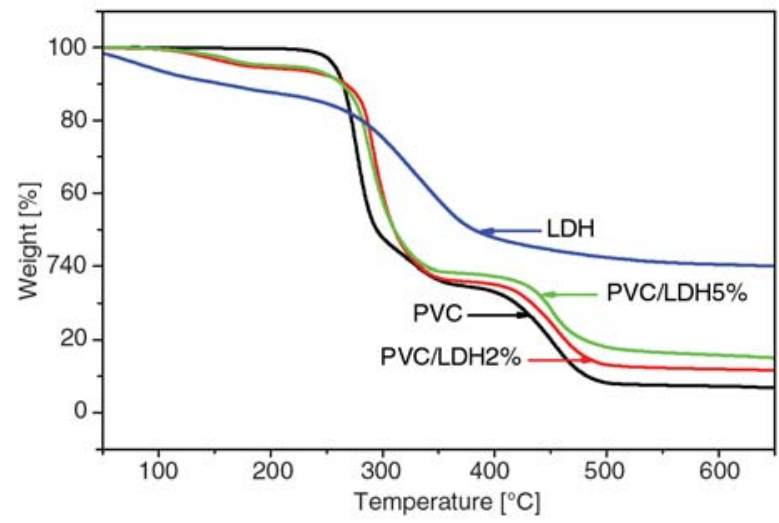

Figure 8. TGA curves of LDH, pristine PVC and its nanocomosites with 2 and $5 \% \mathrm{LDH}$ in $\mathrm{N}_{2}$ at heating rate of $10^{\circ} \mathrm{C} / \mathrm{min}$

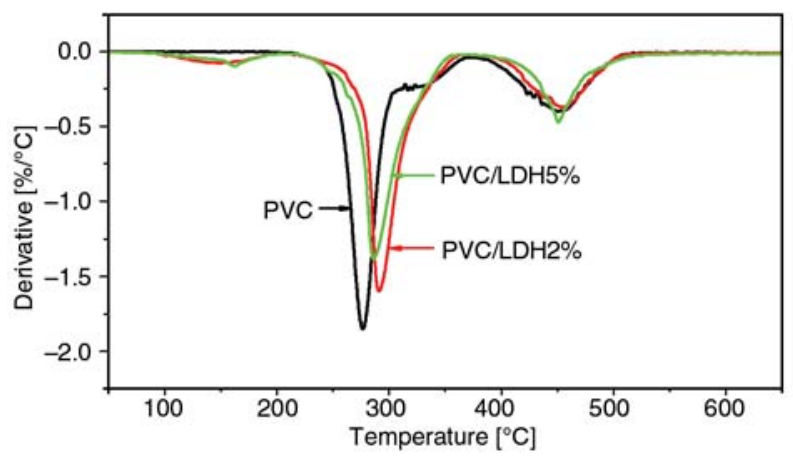

Figure 9. DTG curves of pristine PVC and its nanocomosites with 2 and $5 \% \mathrm{LDH}$ in $\mathrm{N}_{2}$ at heating rate of $10^{\circ} \mathrm{C} / \mathrm{min}$

ites were given in Figures 8 and 9. On heating the pristine $\mathrm{PVC}$ decomposes in the temperature range 
Table 1. TGA data of pure $\mathrm{PVC}$ and $\mathrm{PVC} / \mathrm{LDH}$ nanocomosites in $\mathrm{N}_{2}$ at heating rate of $10^{\circ} \mathrm{C} / \mathrm{min}$

\begin{tabular}{|l|c|c|c|c|}
\hline \multicolumn{1}{|c|}{ Sample } & $\mathbf{T}_{\mathbf{5} \%}\left[{ }^{\circ} \mathbf{C}\right]$ & $\mathbf{T}_{\max } /{ }_{\mathbf{T m a x} 2}\left[{ }^{\circ} \mathbf{C}\right]$ & $\mathbf{R}_{\max } / \mathbf{R}_{\max }\left[{ }^{\circ} \mathbf{C}\right]$ & Char or residue yield at $\mathbf{6 5 0}^{\circ} \mathbf{C}[\mathbf{w t} \%]$ \\
\hline LDH-PK & & & & 40.01 \\
\hline PVC & 257.0 & $276.7 / 450.1$ & $1.85 / 0.40$ & 6.84 \\
\hline PVC/LDH 2\% & 204.4 & $290.0 / 452.0$ & $1.60 / 0.38$ & $11.61\left(7.50^{*}\right)$ \\
\hline PVC/LDH 5\% & 206.0 & $286.2 / 450.7$ & $1.38 / 0.42$ & $15.05\left(8.50^{*}\right)$ \\
\hline
\end{tabular}

$T_{5} \%$ is the temperature for $5 \%$ weight loss; $T_{\max }$ is the temperature at which the rate of weight loss reaches a maxium.

$*$ : theoretical values.

of $250-500^{\circ} \mathrm{C}$ [22]: the first stage is attributed to the elimination of hydrogen chloride molecules followed by the formation of the conjugated polyene sequences, while the second stage to the thermal cracking of the carbonaceous conjugated polyene sequences. As reported, the first step of weight loss for $\mathrm{PVC} / \mathrm{LDH}$ (2 and 5\%) nanocomposites occurs in the range of $120-250^{\circ} \mathrm{C}$ due to the evaporation of physically absorbed water in the intercalated layers and the loss of hydroxide on the LDH, similar to the case of polystyrene/ZnAl-LDH nanocomposites $[3,7]$, poly(vinyl alcohol)/MgAl-LDH nanocomposites [23] and poly(propylene carbonate)/MgAlLDH nanocomposites [24]. The second step of weight loss occurs in the temperature range of $250-385^{\circ} \mathrm{C}$ due to the elimination of hydrogen chloride molecules in PVC chains. The thermal stability of both nanocomposites was obviously enhanced during this stage. The last stage is apparently relevant to the thermal cracking of the carbonaceous conjugated polyene sequences.

The $5 \%$ mass loss temperature $\left(T_{5} \%\right)$, maximum mass loss temperature ( $T_{\max 1}$ and $\left.T_{\max 2}\right)$ and char (or residue) yield values at $650^{\circ} \mathrm{C}$ are summarized in Table 1. It can be seen that $T_{5 \%}$ for two kinds of nanocomposites are decreased by about $52^{\circ} \mathrm{C}$ due to the evaporation of physically absorbed water in the intercalated layers and the loss of hydroxide on the $\mathrm{LDH}$, whilst $T_{\max 1}$ of PVC/LDH nanocomposites with 2 and 5\% LDH are increased by 14 and $10^{\circ} \mathrm{C}$, respectively. When LDH loading is $2 \%$, the PVC nanocomposite shows the highest $T_{\max 1}$ as $290^{\circ} \mathrm{C}$. The maximum mass loss rate $\left(R_{\max 1}\right)$ for PVC nanocomposites with 2 and 5\% LDH are decreased from 1.85 to $1.60,1.38 \% /{ }^{\circ} \mathrm{C}$, respectively. Judging from $T_{\max 1}$ and $R_{\max 1}$, the PVC nanocomposites are more thermally stable than pristine PVC. It is probably because the LDH layers can improve the stability of chlorine atom on the PVC chains, and then retard the thermal degradation rate. But, both $T_{\max 2}$ and $R_{\max 2}$ of nanocom- posites are close to that of pristine PVC, implying that LDH has little effect on the second thermal degradation stage of PVC. That is to say, LDH layers have little effect on the thermal cracking of the carbonaceous conjugated polyene.

It is noteworthy that char yield of $\mathrm{PVC} / \mathrm{LDH}$ nanocomposites with 2 and $5 \% \mathrm{LDH}$ at $650^{\circ} \mathrm{C}$ are significantly increased from 6.84 to $11.61,15.05 \%$, respectively. In Table 1 , the values with $*$ denote theoretical values obtained by calculation, i.e., char yield of $\mathrm{PVC}$ at $650^{\circ} \mathrm{C} \times$ weight of $\mathrm{PVC}$ in $\mathrm{PVC} /$ $\mathrm{LDH}$ nanocomosites + residue yield of LDH-PK at $650^{\circ} \mathrm{C} \times$ weight of LDH-PK in PVC/LDH nanocomposite. For example, for PVC/LDH nanocomposite with $2 \% \mathrm{LDH}, 6.84 \% \times 98 \%+40.01 \% \times 2 \%=$ $7.50 \%$. As can be seen, these experimental values of char yield for nanocomposites are higher than the theoretical values, revealing that the LDH layers in PVC matrix enhance the formation of the char, i.e., the carbonization of the PVC, and stabilize the carbonanceous.

\subsection{Thermal degradation activation energies of PVC and PVC/LDH nanocomposite}

According to the Ozawa method [25], the apparent activation energies $(E)$ were calculated from a linear fitting of $\ln \beta$ versus $1 / T$ plot at different conversion degree $(\alpha)$ and at various heating rates $(\beta)$, where the degree of decomposition $\alpha=\left(W_{0}-W\right) /$ $\left(W_{0}-W_{550^{\circ} \mathrm{C}}\right.$ ) (where $W_{0}$ is the initial weight, $W$ is the actual weight and $W_{550^{\circ} \mathrm{C}}$ is the residual weight at $550^{\circ} \mathrm{C}$ ). In Figure 10, for the PVC, the fitting lines are almost kept parallel to each other in the range of $\alpha<0.6$, indicating the unique degradation mechanism, i.e. the chain stripping mechanism of PVC. But, the fitting lines for PVC are not kept parallel to each other in the range of $\alpha=0.7 \sim 0.9$. This reveals that the degradation mechanism for PVC is complex, corresponding to the second thermal degradation stage of PVC. For the PVC/LDH nano- 

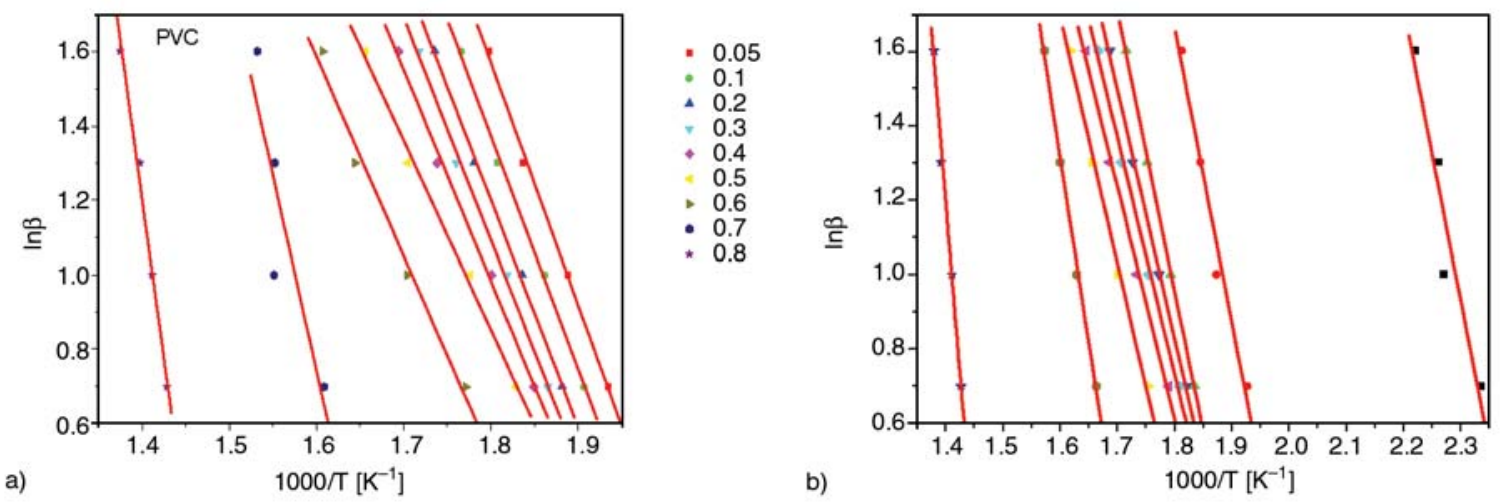

Figure 10. Plots of $\ln \beta$ versus $1 / T$ for PVC (a) and PVC/LDH (2\%) nanocomposite (b) at various conversion degrees according to the Ozawa method

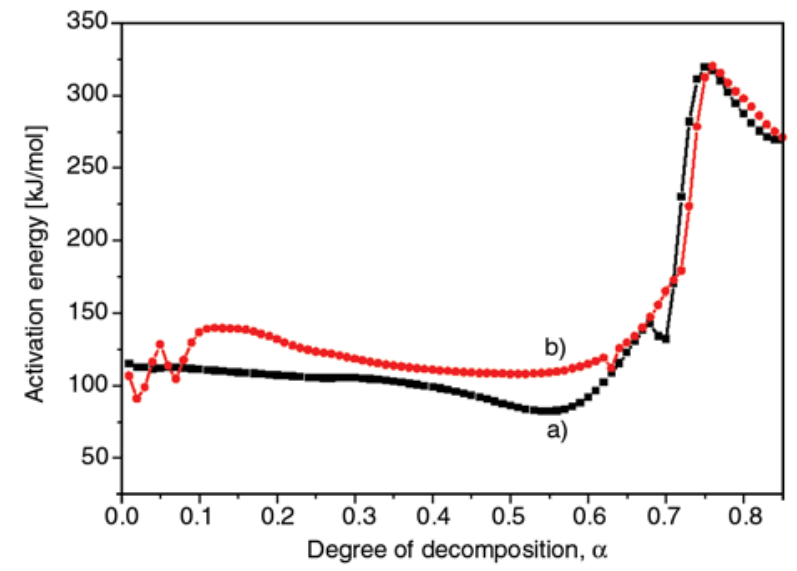

Figure 11. Plot of $E$ versus $\alpha$ for the dynamic degradation of PVC (a) and PVC nanocomposite with $2 \%$ $\mathrm{LDH}(\mathrm{b})$

composite, the fitting lines are also almost kept parallel to each other in the range of $0.1<\alpha<0.65$, not kept parallel to each other in the range of $\alpha=0.7 \sim 0.9$ and $\alpha<0.1$.

It can be seen in Figure 11 that the $E$ versus $\alpha$ for PVC can be separated into two stages(namely $\alpha<0.55$, and $\alpha>0.75$ ) and is in agreement with DTG result (Figure 9). The $E$ versus $\alpha$ for PVC is almost a constant in the range of $\alpha<0.6$, being 90 110 kJ/mol, close to the value of 90 100 kJ/mol reported by Ma et al. [26] and Marcilla and Beltrain [27]. However, the $E$ versus $\alpha$ for PVC/LDH nanocomposite with $2 \% \mathrm{LDH}$ exhibits three stages (namely $\alpha<0.1,0.1<\alpha<0.6$, and $\alpha>0.75$ ). The $E$ of the nanocomposite is complex in the range of $\alpha<0.1$, which is attributed to the evaporation of physically absorbed water in the intercalated layers and maybe the loss of hydroxide on the LDH. The $E$ versus $\alpha$ for the nanocomposite is almost a constant in the range of $\alpha=0.1 \sim 0.6$, which corresponds to the dehydrochlorination of $\mathrm{PVC}$, implying that the presence of LDH layers could not change the dehydrochlorination mechanism of PVC. In the range of $\alpha=0.1 \sim 0.6$, the nanocomposite increases the activation energy by $10 \sim 26 \mathrm{~kJ} / \mathrm{mol}$, relative to pristine PVC. It may reveal that the presence of LDH layers improves the stability of chlorine atom on the PVC chains and represses the dehydrochlorination of PVC. However, the mechanism of thermal stability of LDH layers in the PVC matrix must further be studied in future.

Interestingly, in the range of $\alpha>0.75$, the apparent activation energies of pristine $\mathrm{PVC}$ are close to that of the nanocomposite, indicating that the LDH layers have little influence on the thermal degradation stage of PVC at high temperature, i.e. the thermal cracking of PVC. This is in agreement with DTG results.

\section{Conclusions}

The PVC/MgAl-LDH nanocomposites were synthesized by novel exfoliation restacking method using laurylether phosphate modified LDH. Despite the ardent discussion of the nano-dispersion is put forward an argument in recent literatures. The conventional methods of characterizing dispersion, such as XRD and TEM were primarily invoked in the paper. Within the experimental error the nanodispersion of LDH layers in the PVC matrix has been verified by the observation of $d_{003}$ XRD diffraction peak of LDH and the observation of TEM image. The glass transition temperature of $\mathrm{PVC}$ phases in the PVC/LDH nanocomposites are slightly lower than that of pristine PVC because of the weakened interaction between macromolecular 
chains in nanocomposites due to the interposition of $\mathrm{LDH}$. The $5 \%$ weight loss temperature of the nanocomposites was also decreased owing to the evaporation of physically absorbed water in the intercalated layers and the loss of hydroxide on the LDH. Moreover, the dehydrochlorination temperature $\left(T_{\max 1}\right)$ and the char residue at $650^{\circ} \mathrm{C}$ of the nanocomposites were significantly increased in the presence of LDH. However, the thermal degradation temperature of the dehydrochlorinated PVC turned out to be little affected by the presence of LDH. The apparent activation energies calculated by the method of Flynn-Wall-Ozawa in nitrogen at four different heating rates show that the nanocomposite increased the apparent activation energies by 10-26 kJ/mol when compared with pristine PVC. Seemingly, the presence of LDH layers seems to improve the stability of the PVC chains through retarding the dehydrochlorination of PVC.

\section{References}

[1] Nyambo C., Wilkie C. A.: Layered double hydroxides intercalated with borate anions: Fire and thermal properties in ethylene vinyl acetate copolymer. Polymer Degradation and Stability, 94, 506-512 (2009). DOI: $10.1016 /$ j.polymdegradstab.2009.02.001

[2] Lonkar S. P., Morlat-Therias S., Caperaa N., Leroux F., Gardette J. L., Singh R. P.: Preparation and nonisothermal crystallization behavior of polypropylene/ layered double hydroxide nanocomposites. Polymer, 50, 1505-1515 (2009). DOI: $\underline{10.1016 / j . p o l y m e r .2009 .01 .031}$

[3] Qiu L., Chen W., Qu B.: Exfoliation of layered double hydroxide in polystyrene by in-situ atom transfer radical polymerization using initiator-modified precursor. Colloid and Polymer Science, 283, 1241-1245 (2005). DOI: $10.1007 / \mathrm{s} 00396-005-1305-6$

[4] Hsueh H., Chen C-Y.: Preparation and properties of LDHs/polyimide nanocomposites. Polymer, 44, 11511161 (2003). DOI: $\underline{10.1016 / \mathrm{S} 0032-3861(02) 00887-\mathrm{X}}$

[5] Costa F. R., Abdel-Goad M., Wagenknecht U., Heinrich G.: Nanocomposites based on polyethylene and $\mathrm{Mg}$-Al layered double hydroxide. I. Synthesis and characterization. Polymer, 46, 4447-4453 (2005). DOI: $10.1016 /$ j.polymer.2005.02.027

[6] Zammarano M., Franceschi M., Bellayer S., Gilman J. W., Meriani S.: Preparation and flame resistance properties of revolutionary self-extinguishing epoxy nanocomposites based on layered double hydroxides. Polymer, 46, 9314-9328 (2005). DOI: $10.1016 /$ j.polymer.2005.07.050
[7] Qiu L., Chen W., Qu B.: Structural characterization and thermal properties of exfoliated polystyrene/ZnAl layered double hydroxide nanocomposites prepared via solution intercalation. Polymer Degradation and Stability, 87, 433-440 (2005).

DOI: 10.1016/j.polymdegradstab.2004.09.009

[8] Ulibarri M. A., Pavlovic I., Barriga C., Hermosín M. C., Cornejo J.: Adsorption of anionic species on hydrotalcite-like compounds: Effect of interlayer anion and crystallinity. Applied Clay Science, 18, 17 27 (2001). DOI: $\underline{10.1016 / \mathrm{S} 0169-1317(00) 00026-0}$

[9] Leroux F., Besse J-P.: Polymer interleaved layered double hydroxide: A new emerging class of nanocomposites. Chemistry of Materials, 13, 3507-3515 (2001). DOI: $\underline{10.1021 / \mathrm{cm} 0110268}$

[10] Wu Q., Sjastad A. O., Vistad Ø. B., Knudsen K. D., Roots J., Pedersen J. S., Norby P.: Characterization of exfoliated layered double hydroxide ( $\mathrm{LDH}, \mathrm{Mg} / \mathrm{Al}=3$ ) nanosheets at high concentrations in formamide. Journal of Materials Chemistry, 17, 965-971 (2007). DOI: $10.1039 / \mathrm{b} 612389 \mathrm{a}$

[11] Adachi-Pagano M., Forano C., Besse J-P.: Delamination of layered double hydroxides by use of surfactants. Chemical Communications, 1, 91-92 (2000). DOI: $10.1039 / \mathrm{a} 908251 \mathrm{~d}$

[12] Hibino T., Jones W.: New approach to the delamination of layered double hydroxides. Journal of Materials Chemistry, 11, 1321-1323 (2001).

DOI: $10.1039 / \mathrm{b} 101135 \mathrm{i}$

[13] Bao Y-Z., Huang Z-M., Weng Z-X.: Preparation and characterization of poly(vinyl chloride)/layered double hydroxides nanocomposite via in situ suspension polymerization. Journal of Applied Polymer Science, 102, 1471-1477 (2006). DOI: 10.1002/app.24317

[14] Chen G.: Preparation of a poly(vinyl chloride)/layered double hydroxide nanocomposite with a reduced heavy-metal thermal stabilizer. Journal of Applied Polymer Science, 106, 817-820 (2007).

DOI: 10.1002/app.26514

[15] Liu J., Chen G., Yang J., Ma Y.: New facile preparation of a poly(vinyl chloride)/layered double hydroxide nanocomposite via solution intercalation. Chemistry Letters, 36, 1454-1455 (2007).

DOI: $10.1246 / \mathrm{cl} .2007 .1454$

[16] Liu J., Chen G., Yang J.: Preparation and characterization of poly(vinyl chloride)/layered double hydroxide nanocomposites with enhanced thermal stability. Polymer, 49, 3923-3927 (2008). DOI: 10.1016/j.polymer.2008.07.014

[17] Wang D., Wilkie C. A.: Preparation of PVC-clay nanocomposites by solution blending. Journal of Vinyl and Additive Technology, 8, 238-245 (2002). DOI: $\underline{10.1002 / \mathrm{vnl} .10369}$ 
[18] Costantino U., Marmottini F., Rocchetti M., Vivani R.: New synthetic routes to hydrotalcite-like compounds-characterization and properties of the obtained materials. European Journal of Inorganic Chemistry, 1998, 1439-1446 (1998).

DOI: 10.1002/(SICI)1099-0682(199810)1998:10 $\leq 1439:$ :AID-EJIC1439>3.0.CO;2-1

[19] Chibwe K., Jones W.: Intercalation of organic and inorganic anions into layered double hydroxides. Journal of the Chemical Society, Chemical Communications, 14, 926-927 (1989).

DOI: $\underline{10.1039 / C 39890000926}$

[20] Yang D-Y., Liu Q-X., Xie X-L., Zeng F-D.: Structure and thermal properties of exfoliated PVC/layered silicate nanocomposites via in situ polymerization. Journal of Thermal Analysis and Calorimetry, 84, 355359 (2006).

DOI: $10.1007 / \mathrm{s} 10973-005-6936-9$

[21] Liu X., Wu Q.: PP/clay nanocomposites prepared by grafting-melt intercalation. Polymer, 42, 1001310019 (2001).

DOI: $10.1016 / \mathrm{S} 0032-3861(01) 00561-4$

[22] Gong F., Feng M., Zhao C., Zhang S., Yang M.: Thermal properties of poly(vinyl chloride)/montmorillonite nanocomposites. Polymer Degradation and Stability, 84, 289-294 (2004).

DOI: $10.1016 /$ j.polymdegradstab.2003.11.003
[23] Li B., Hu Y., Zhang R., Chen Z., Fan W.: Preparation of the poly(vinyl alcohol)/layered double hydroxide nanocomposite. Materials Research Bulletin, 38, 1567-1572 (2003).

DOI: $10.1016 / \mathrm{S} 0025-5408(03) 00203-4$

[24] Du L., Qu B., Meng Y., Zhu Q.: Structural characterization and thermal and mechanical properties of poly(propylene carbonate)/MgAl-LDH exfoliation nanocomposite via solution intercalation. Composites Science and Technology, 66, 913-918 (2006).

DOI: 10.1016/j.compscitech.2005.08.012

[25] Ozawa T.: A new method of analyzing thermogravimetric data. Bulletin of the Chemical Society of Japan, 38, 1881-1886 (1965).

DOI: $\underline{10.1246 / \text { bcsj. } 38.1881}$

[26] Ma S., Lu J., Gao J.: Study of the low temperature pyrolysis of PVC. Energy and Fuels, 16, 338-342 (2002).

DOI: $10.1021 /$ ef0101053

[27] Marcilla A., Beltrain M.: Thermpgravimetric kinetic study of poly(vinyl chloride) pyrolysis. Polymer Degradation and Stability, 48, 219-229 (1995). DOI: 10.1016/0141-3910(95)00050-V 